\title{
A Randomized Trial of Continuous Versus Intermittent Skin-to-Skin Contact After Premature Birth and the Effects on Mother-Infant Interaction
}

Charlotte Sahlén Helmer, Ulrika Birberg Thornberg, Anneli Frostell, Annica Ortenstrand and Evalotte Morelius

The self-archived postprint version of this journal article is available at Linköping University Institutional Repository (DiVA):

http://urn.kb.se/resolve?urn=urn:nbn:se:liu:diva-168288

N.B.: When citing this work, cite the original publication.

Sahlén Helmer, C., Birberg Thornberg, U., Frostell, A., Ortenstrand, A., Morelius, E., (2020), A Randomized Trial of Continuous Versus Intermittent Skin-to-Skin Contact After Premature Birth and the Effects on Mother-Infant Interaction, Advances in Neonatal Care, 20(3), E48-E56.

https://doi.org/10.1097/ANC.0000000000000675

Original publication available at:

https://doi.org/10.1097/ANC.0000000000000675

Copyright: Lippincott, Williams \& Wilkins

http://www.lww.com/ 


\section{A randomized trial of continuous versus intermittent skin-to- skin contact after premature birth and the effects on mother- infant interaction}

\section{Abstract}

\section{Background}

Premature birth affects opportunities for interaction between infants and mothers. Skin-toskin contact (SSC) is standard care in neonatal care but has not been sufficiently studied regarding the effects on interaction between preterm infant and mothers.

\section{Purpose}

To compare interaction between preterm infants and their mothers after continuous versus intermittent SSC from birth to discharge. A secondary aim was to study a potential doseresponse effect between time in SSC and quality of interaction.

\section{Methods}

Families were randomly assigned to either continuous ( $n=17)$ or intermittent $(n=14)$ SSC before delivery. Interaction was measured from videotapes of a Still-Face Paradigm collected at four months corrected age. Face-to-face interaction was coded according to Ainsworth's Maternal Sensitivity Scales and Maternal Sensitivity and Responsivity Scales-R. Doseresponse correlations were calculated between mean time spent in SSC and each of the interaction scales.

\section{Results}

There were no statistically significant differences between groups in maternal interactive behavior towards her infant regarding sensitivity, interference, availability, acceptance, 
withdrawal or intrusivity. There was no correlation between mean time in SSC and quality of interaction.

\section{Implications for Practice}

Continuous SSC from birth to discharge was not superior to intermittent SSC concerning mother-infant interaction between preterm infants and their mothers at four months corrected age. However, compared to other studies, mean time in SSC was high also in the intermittent group.

\section{Implications for Research}

Further studies are needed to find out how interaction between parents and preterm infants can be improved, supported and facilitated in the NICU and if there is an optimal dose for SSC.

\section{Keywords}

Premature infant, Neonatal Intensive Care, Mother Child relations, Kangaroo Mother Care, Behavior, Sensitivity, Parenting, Attachment

\section{Background and Significance}

Every year around 15 million infants are born preterm worldwide. ${ }^{1}$ Preterm infants in need of intensive care are often separated from their mothers, which interrupts and hinders interaction. ${ }^{2}$ Furthermore, hospital routines, medical equipment and invasive procedures affect parental involvement. ${ }^{3,4}$ Lack of mother and preterm infant interaction may affect the infant's developing brain negatively, resulting in long-term consequences 
for emotional, behavioral and cognitive functions. ${ }^{1,5-8}$ Brain development relies on both inborn and environmental factors and there is an interdependency between behaviors and brain development. ${ }^{9}$ Mother-infant interaction is by Brazelton (1975), described as an act where the mother and the infant modify their behaviors depending on the feedback provided by the other ${ }^{10}$ A review of Neel (2018) found parental warmth to improve preterm infant behavioral outcome, as well as associations between parental sensitivity and improved infant development. ${ }^{11}$ However, a maternal behavior less sensitive has been related to difficulties in understanding the preterm infant's behavior. ${ }^{12}$ Additionally, Korja et al (2012) showed shortage in preterm infants' interactions and differences in mothers' interaction style. ${ }^{13}$ However, there is contrasting evidence showing no differences in sensitivity or responsivity towards the infant between mothers to preterm infants compared to full-term infants, ${ }^{14,15}$ suggesting that it is a mother's interactive behavior that contributes to infant attachment, ${ }^{16}$ and development, ${ }^{17}$ rather than the prematurity of the infant.

The birth of a preterm infant evokes various feelings among parents. A qualitative study described how both mothers and fathers experienced emotional closeness and self-reliance when they could interact and take care of their infant. On the contrary they felt separated when their contribution in the care of the infant was limited ${ }^{18}$ This was confirmed in a qualitative study by Baum et al (2012), where the preterm birth and separation contributed to mother's feelings of distress, guilt, bonding difficulties and emptiness. ${ }^{19} \mathrm{~A}$ meta-analysis found some reduction in the increased risk for postpartum depression among preterm mothers practicing SSC. ${ }^{20}$ Mothers have described how they could more easily relax when 
caring for their preterm infant in $\mathrm{SSC}_{,}^{21}$ and nurses suggest that SSC strengthens attachment and the parents' feelings of knowing the infant. ${ }^{22}$

However, the results for how SSC influences interaction between the mother and the preterm infant are still inconclusive. Athanasopoulou and Fox found in a review some evidence for improved interaction between preterm infants and parents after SSC, but they also highlighted several methodological limitations to be considered. Data on care given, duration of SSC, if the assessors were blinded and descriptive data on maternal and infant demographics were incomplete. ${ }^{23} \mathrm{~A}$ randomized controlled study with a late follow-up found when the child was ten years, a more reciprocal mother-child relationship compared to the control group. This study had a case-matched design where preterm infants either experienced SSC for one hour a day for 14 consecutive days during the neonatal care period, or standard incubator care without SSC. ${ }^{24}$ Another study reporting on maternal- infant interaction found evidence that kangaroo mother care, which includes SSC as one major part of the intervention, increase the symmetry co-regulation between mother and low birthweight infants at six month. ${ }^{25}$ In contrast, Chiu and Anderson found no differences in interaction after SSC. In their study, the dyads randomized to intervention all experienced SSC within the first two days, for an average of 1.3 hours each time while the control group received blanket-holding. ${ }^{26}$ Hence, it is not clear whether interaction between mothers and preterm infants improves with SSC, or if there is a dose-response effect.

The primary aim was to compare interaction between preterm infants and their mothers after continuous versus intermittent (SSC). A secondary aim was to evaluate the doseresponse effect between time in SSC and quality of interaction. Our hypothesis was that continuous SSC can improve mother-infant interaction measured as sensitivity, interference, 
availability, acceptance, withdrawal and intrusiveness and that the more time spent in SSC the better interaction.

\section{Methods}

\section{Design}

The design is a two-center, comparative, randomized study with two groups at two hospitals in Sweden. This study is the second part of a larger trial studying the effects of SSC. Using the same sample, continuous SSC proved to decrease infants' cortisol reactivity and increase coregulation of cortisol between mothers and infants. There were no differences between groups in breastfeeding and depression (Edinburgh Postnatal Depression Scale). ${ }^{27}$ The present study focuses on mother-infant interaction as this heretofore have not been sufficiently studied. Continuous SSC was defined as beginning in the delivery room and continuing for almost 24 hours a day until discharge. Intermittent SSC was defined as parents having the opportunity to practice as much SSC as they liked, i.e. standard care at the included NICUs.

\section{Sample}

The hospitals were one level-3 NICU at Linköping University Hospital and one level-2 NICU at Sachs' Children's Hospital in Stockholm. The NICUs participating in this study are familycentered wards with 17 and 13 infant beds respectively at the time of inclusion. The NICUs had separate rooms for every family, including a bed for the infant and both parents. In both NICUs, SSC was part of the care and the parents were expected to participate in the care of the infant as soon and as much as possible.

Written and oral information about the study was provided to the parents and written consent was obtained prior to the study. Eligible families were recruited between April 2008 and April 2012 and randomized to continuous or intermittent SSC before delivery. It was a 
consecutive sampling where participating families were administered sequentially numbered sealed envelopes for randomization. A group of nurses at both hospitals enrolled participants. Inclusion criteria were Swedish speaking, healthy women about to give birth vaginally to a single preterm infant between gestational age weeks $32^{+0}-35^{+6}$. Exclusion criteria were infants with congenital malformations.

\section{Instruments}

Data on the preterm infant's health status, gender, post menstrual age at birth and discharge, birth weight and weight at discharge was collected from the medical chart. The mothers responded to questionnaires concerning number of children, their age, marital status, education and infant's weight, feeding status at four months and depression symptoms.

The Still-Face Paradigm was used during videotaped sessions of mother-infant interaction. The Still-Face Paradigm follows a systematic protocol observing interaction in three phases. The procedure is used for research purposes and offers a robust effect regardless of variations such as gender or procedural variations. ${ }^{28}$ The dyad interacts for two minutes, followed by two minutes where the mother looks at her infant with a neutral face without interaction. This is to investigate the infant's ability to regulate and to examine how important the interactive mutuality is for the infant. After the neutral phase the mother is instructed to interact with her infant again for an additional two minutes ${ }^{29}$ The interaction was later coded with two instruments, Ainsworth's Maternal Sensitivity Scales and Maternal Sensitivity and Responsivity Scales. Ainsworth's Maternal Sensitivity Scales, developed from the attachment theory, consists of four scales. The first scale measures the mother's sensitivity towards her infant and ranges from 1 (a mother who is highly insensitive to the infant) to 9 (a mother who is highly sensitive). The second scale measures interference 
versus cooperation towards the infant with the endpoints 1 (a highly interfering mother) to 9 (a mother that is guiding her infant rather than controlling). The third scale measures availability and ranges from 1 (a highly neglecting mother) to 9 (a highly accessible mother). Finally, the fourth scale measures acceptance versus rejection towards the infant's needs with endpoints 1 (a mother who is clearly rejecting) and 9 (a highly accepting mother). ${ }^{30}$ One review of different observational measures of interaction describes the scales as theoretically well-grounded, ${ }^{31}$ another how the scales are still well used and continues to influence the development of other tools. ${ }^{32}$ The scales have been successfully tested for validity and reliability. ${ }^{31}$ The Ainsworth's Maternal Sensitivity Scales are commonly used for infants 3 months to 24 months of age. ${ }^{33}$

The Maternal Sensitivity and Responsivity Scales, MSRS-R consists of three scales. The scales have a five-point rating and the interaction is coded during phase one and phase three of the Still-Face. The first scale measures the mother's sensitivity; whether she manages to detect the infant's communication signals, and how she interprets and responds to the infant, from 1 (a mother with an ignoring behavior) to 5 (a very responsive mother). The second scale measures withdrawal on a reversed scale from 1 (a mother who is engaged in her infant throughout the interaction) to 5 (a consistently under-involved mother). The third scale measures intrusiveness on a reversed scale from 1 (mother is aware of the infant's activities but does not intrude) to 5 (a strongly over-controlling mother). ${ }^{34}$ The MSRS-R were used as they were designed to measure interaction during the Still-Face Paradigm, although there is limited information about the validity of these scales.

\section{Statistical Analysis}

To calculate possible differences between groups as regard to postmenstrual age at birth and discharge, birthweight, weight at discharge and weight at four months, and finally 
mother's age, independent sample t-test was used. To calculate possible differences between groups in terms of gender, siblings, marital status and mother's education, chisquare was used. To calculate possible differences in mean time in SSC, independent sample t-test was used. Mann-Whitney U-test ${ }^{35}$ was used to calculate possible differences in interaction behavior between the two groups.

Spearman's rho was used to calculate possible dose-response correlations between mean time for SSC, irrespectively of group, and interaction scales. The continuous and intermittent SSC groups were combined into one group, and two timeframes were chosen to calculate dose-response, namely meantime in SSC for day 1-3 when all families were still enrolled at the hospital; and days 1-7 because after day 7 most families were discharged from hospital. Sample size was based on primary outcome and previous studies of salivary cortisol in preterm infants. ${ }^{27,36}$ To analyze data the statistical software SPSS version 25 was used. If $p<$ 0.05 , the result was deliberated as statistically significant.

\section{Procedures}

If the family agreed to participate and were allocated to continuous SSC, the infant was immediately after birth placed in an upright position on the mother's chest and stayed there when transferred to the NICU. If the family was allocated to intermittent SSC, the infant was separated from the mother in the delivery room and transferred to the NICU. Since Blomqvist et al previously have shown that parents in Swedish NICUs are reliable recorders of SSC, ${ }^{37}$ parents in continuous SSC were instructed to document who provided SSC, and if they were off SSC for any reason. Parents in the intermittent group registered when and for how long they provided SSC. All included parents received a structured education provided by a NIDCAP ${ }^{\circledR}$ certified nurse on how to look for and respond to a preterm infant's signals. 
NIDCAP, Newborn Individualized Developmental Care and Assessment Program, is a relationship-based model taking the competence of the infant and family in consideration striving to comfort the infant and improve long-term outcome. ${ }^{38}$ Apart from this structured education, the families were given standard care that is parents having the opportunity to stay at the hospital and participate in the care of their preterm infant around the clock.

Follow-up were conducted between August 2008 and August 2012, when the infant was four months corrected age. A home visit, including data collection through questionnaires and a videotaped face-to-face interaction between mother and infant, the Still-Face Paradigm, was completed. In this study the dyad was filmed with the infant in a bouncing cradle and the mother in front of the infant, face to face. A mirror was placed beside the infant to be able to catch the mother and the infant simultaneously. The interaction in the dyad was later coded from video according to Ainsworth's Maternal Sensitivity Scales and the Maternal Sensitivity and Responsivity Scales (MSRS-R). The trained coder (CSH) did not participate in the videotaping and was blinded to randomization and time in SSC. Approval for the study was granted by the Regional Ethical Review Board at Linköping University (M30-07).

\section{Results}

Families with 42 preterm infants agreed to participate in the study. Of these families, 23 families were randomized to continuous SSC and 19 families were randomized to intermittent SSC. Due to randomization before birth of the infant, five families were excluded after birth. A total of six families withdrew from the study, resulting in 17 families receiving continuous SSC and 14 families receiving intermittent SSC (Figure 1). There were no significant differences in descriptive data between the two groups (Table 1). Even though the parents in the intermittent SSC group had the opportunity to practice as much SSC as they 
wanted, there was a significant difference between the two groups when comparing the hours of SSC (Table 2). After seven days several families were discharged, resulting in too few families to perform calculations. There were no harms or unintended effects in any of the two groups. For safety reasons, the infants wore equipment measuring their saturation and heart rate during SSC as there is a risk for sudden unexpected collapse if the infants' airways are obstructed during SSC. ${ }^{39}$ Parents were also instructed to observe their infant and received information on how to safely position their infant.

Table 3 shows the results from the Ainsworth's Maternal Sensitivity Scales and the MSRS-R for the two groups respectively. Interaction scores did not differ significantly between the continuous SSC group and the intermittent SSC group.

When the groups were combined into one group, mean time in SSC per day, for days 1-3 was 14.15 hours, (SD 8.62) $n=31$. For days $1-7$ mean time was 12.80 hours, (SD 8.24) $n=26$. No significant correlations were found between mean time in SSC and interaction scales, neither for days 1-3 nor for days 1-7 (Table 4).

\section{Discussion}

Our hypothesis that continuous SSC can improve mother-infant interaction was not supported. Continuous SSC was not superior to intermittent SSC for improving mothers' sensitivity, interference, availability, acceptance, withdrawal or intrusiveness measured by Ainsworth's Maternal Sensitivity Scales and MSRS-R at four months corrected age. However, the intermittent group had a high level of SSC for the first week comparable to the intervention group in a study by Gathwala, although that group had SSC for a longer period of time since they continued SSC at home after discharge. ${ }^{40}$ According to a systematic review by Athanasopoulou and Fox, SSC was not encouraged, accepted, or sometimes not even 
documented for the included control groups. The infants allocated to control groups were mainly cared for in incubators or held wrapped in blankets. ${ }^{23}$ Because of ethical reasons, it was not possible to have a control group not allowed to practice SSC at all in our study, since SSC is practiced in all Swedish NICUs. ${ }^{41}$

Chiu \& Anderson found no differences in interaction between groups, ${ }^{26}$ in line with results in our study. In fact, the SSC infants (experiencing SSC at an average of 11.6 occasions with an average of 1.3 hours each time) had lower interaction scores at six months compared to the control group where the infants were held wrapped in blankets. ${ }^{26}$ This is contrasting evidence compared to Feldman's study where a positive outcome on interaction was seen after ten years. ${ }^{24}$ In another study comparing early SSC and separation postpartum, SSC affected mother-infant interaction in a positive way measured when the infant was one year old. ${ }^{42}$ Maybe it is too early to study improvements in interaction after SSC when the infant is younger than one year; the effects might not appear until later. In our study we choose four months for follow up as Ainsworth's Maternal Sensitivity Scales is commonly used during infancy. Four months age is also a suitable time for studying behavior since infants at that age are more willing to interact. We have previously used Ainsworth's Maternal Sensitivity Scales around this age with satisfying results. ${ }^{43}$

Concerning the mothers' withdrawal behavior, measured by the MSRS-R, our findings are similar to a study from Meijssens et al, where mothers showed more engaged and supportive behavior in both groups. ${ }^{44}$ The video-recorded Still-Face-situation might have influenced the interaction, making the mothers willing to show the dyads interactive communication and therefore less withdrawal behavior was displayed. 
SSC makes a foundation for contact and thus increased interaction, a way for the mother to detect signals and respond to her infant. But SSC is not equal to interaction. There might be a need for a more specific intervention when it comes to enhancing interaction in this fragile dyad. Beebe et al have shown that an early intervention facilitating contact between the mother and the preterm infant improved interaction and communication at the age of four months corrected age. ${ }^{45}$ Mothers have pointed to difficulties in seeing their newborn, ${ }^{46}$ and nurses have stated that face-to-face interaction may be obstructed due to the position of the infant in SSC, the mother not being able to see the face of her infant and read its facial cues. ${ }^{22}$ This could be compared to when the mother holds the infant in her arms, which increases the possibility for face-to-face interaction. ${ }^{26}$ Early, cue-based interventions to improve interaction, ${ }^{47}$ not always requiring an excessive amount of intervention, have been found to be most effective in improving parental sensitivity. ${ }^{48,49}$ Parental embodied mentalizing is the parents' ability to be aware of and guide the infant's physical expressions, to integrate what is observed with the feelings of the infant. It focuses on how the interactive movements are made, how the dyad approaches one another and when, reflecting their mental meeting ${ }^{50}$ Regarding this, continuous SSC might not be powerful enough to have a superior effect on parent-infant interaction compared to intermittent SSC. Personal competences or inherited behaviors may be more important. There might be a need for something more to tune in to the infants needs and signals, something more specific to raise the awareness of the infant through the bodily experience of the infant, than to just continuously be in SSC. This could also explain the lack of a doseresponse effect seen in the present study. Moreover, attachment behavior is considered to be transferred from generation to generation. A longitudinal study comparing interactions over two generations found a comparable parental style between generations, ${ }^{51}$ which 
indicates that changing parental interactive behaviors may need more powerful interventions than SSC.

Parents practicing SSC have previously described SSC as being practically challenging, affecting time of one's own, time to eat and to express breastmilk. ${ }^{52}$ Feelings of being insufficient for their infants' needs and on the same time being frustrated because of their own unfulfilled needs may have a negative influence on the quality of parent-infant interaction. In another qualitative study it has recently been described how mothers to late preterm infants found separation after birth difficult and appreciated SSC. At the same time, they also experienced lack and inconsistency of support from staff and referred to some staff's negative attitudes to SSC. ${ }^{53}$ Continuous SSC has also been described by nurses to be tiring for parents and that parents may feel insufficient if they can't meet the demands of having the infant continuously skin-to-skin. ${ }^{22}$

Interestingly the group randomized to intermittent SSC in the present study used an average of six hours of SSC per day during their first week of hospitalization. This is more hours than we expected from a clinical point of view and more than has been described in other studies. ${ }^{23}$ Therefore, the intermittent SSC group almost became an intervention group in our study. Simply receiving information about SSC and watching other parents practicing SSC may have increased their use. Skin-to-skin contact has several documented benefits, for instance less stress, increased co-regulation, and less spouse relationship problems, ${ }^{27}$ which is important to inform the parents about so they can make their own decisions.

Preterm birth is a risk factor for impaired developmental outcome, ${ }^{5}$ a non-sensitive parental style can further impact negatively on cognition. ${ }^{11} \mathrm{~A}$ well-functioning parent-infant 
interaction is therefore something that has to be raised awareness of even in a very technical NICU environment, traditionally more focused on infants' medical progress. It is of great importance to bring clarity in what sort of interventions these fragile dyads' interactive communication would benefit the most from, to ensure improved infant development but also to support preterm parents in their often traumatic and stressful situation.

\section{Strengths and limitations}

Previous studies do not always state how many hours the dyad has practiced SSC, when SSC was initiated, or whether the infants' medical situation or for example mothers' depression symptoms may have had an impact on mother-infant interaction. ${ }^{23}$ It is important to include such information in forthcoming studies, in order to increase the possibility of future metaanalyses. Another possible confounder could be breastfeeding, which partly includes SSC and has been described as affecting interaction positively. ${ }^{22}$ Some benefits of the present study are that there were no significant differences in demographics between groups, neither for mothers nor for infants. Neither were there differences in postpartum depression symptoms nor breastfeeding. Moreover, time of initiation as well as time in SSC for the entire hospital stay is clearly stated. Further, videotaped data yielded a descriptive and reliable view of the interaction. Even though the videotaping situation may have influenced the interaction, the situation was the same for all mothers and infants and therefore should not have had an impact on group results.

The MSRS-R were used even though the validity of the scales is insufficiently documented. However, since MSRS-R showed the same results as the Ainsworth's Maternal Sensitivity Scales the criterion validity of the MSRS-R is strengthened by this study.

For safety reasons the families were recommended not to use SSC at home, however, we have no data on the use of SSC after discharge from hospital, which potentially can have 
affected the results. Another limitation is the sample size, which was based on cortisol reactivity. The sample size is small, but comparable with other studies that measure sensitivity, ${ }^{54-57}$ and the results are supported by the high $p$-values. Therefore, the study is a contribution of knowledge to a field that has not been sufficiently investigated.

\section{Conclusions}

Continuous SSC was not superior to intermittent SSC concerning interaction between moderate to late preterm infants and their mothers, although, the intermittent group had SSC comparable with intervention groups in other studies. No dose-response effect was found between time in SSC and interaction. Further studies are needed to find out how interaction between parents and preterm infants can be improved, supported and facilitated in the NICU and if there is an optimal dose for SSC.

\section{Acknowledgements}

The authors would like to gratefully acknowledge participating families, Lisbet de Jounge,

Birgitta Lundin, and staff members at the Neonatal Intensive Care Units at Linköping University Hospital and at Sachs' Children's Hospital in Stockholm.

\section{References}

1. World Health Organization (WHO). Preterm birth. http://www.who.int/mediacentre/factsheets/fs363/en/. Published February, 2018. Accessed August 28, 2019.

2. Nyqvist KH, Anderson GC, Bergman N, et al. State of the art and recommendations. Kangaroo mother care: application in a hightech environment. Breastfeeding Review. 2010;18(3):812819.

3. Jiang SY, Warre R, Qiu XM, O'Brien K, Lee SK. Parents as practitioners in preterm care. Early Human Development. 2014;90(11):781-785. 
4. Baylis R, Ewald U, Nyqvist KH, Rubertsson C, Blomqvist YT, Gradin M. First-time events between parents and preterm infants are affected by the designs and routines of neonatal intensive care units. Acta Paediatrica. 2014;103(10):1045-1052.

5. Lundequist A, Böhm B, Lagercrantz H, Forssberg H, Smedler A-C. Cognitive outcome varies in adolescents born preterm, depending on gestational age, intrauterine growth and neonatal complications. Acta Paediatrica. 2015;104(3):292-299.

6. Månsson J, Stjernqvist K. Children born extremely preterm show significant lower cognitive, language and motor function levels compared with children born at term, as measured by the Bayley- III at 2.5 years. Acta Paediatrica. 2014;103(5):504-511.

7. Johnson S, Marlow N. Early and long-term outcome of infants born extremely preterm. Archives of Disease in Childhood. 2017;102(1):97-102.

8. Braarud HC, Slinning K, Moe V, et al. Relation between social withdrawal symptoms in fullterm and premature infants and depressive symtoms in mothers: a longitudinal study. Infant Mental Health Journal. 2013;34(6):532-541.

9. Stiles J. On genes, brains, and behavior: Why should developmental psychologists care about brain development? Child Development Perspectives. 2009;3(3):196-202.

10. Brazelton TB, Tronick E, Adamson L, Als H, Wise S. Early mother-infant reciprocity. Ciba Foundation symposium. 1975(33):137-154.

11. Neel MLM, Stark AR, Maitre NL. Parenting style impacts cognitive and behavioural outcomes of former preterm infants: A systematic review. 2018;44(4):507-515.

12. Butti N, Borgatti R, Urgesi C, Montirosso R. Maternal sensitivity is associated with configural processing of infant's cues in preterm and full-term mothers. Early Human Development. 2018;125:35-45.

13. Korja R, Latva R, Lehtonen L. The effects of preterm birth on mother-infant interaction and attachment during the infant's first two years. Acta Obstetricia et Gynecologica Scandinavica. 2012;91(2):164-173.

14. Wolke D, Bilgin A. Maternal Sensitivity in Parenting Preterm Children: A Meta-analysis. Pediatrics. 2015;136(1):177-193.

15. Neri E, Agostini F, Baldoni F, Facondini E, Biasini A, Monti F. Preterm infant development, maternal distress and sensitivity: The influence of severity of birth weight. Early Human Development. 2017;106-107:19-24.

16. Hall R, Hoffenkamp H, Tooten A, Braeken J, Vingerhoets A, Bakel H. Longitudinal Associations Between Maternal Disrupted Representations, Maternal Interactive Behavior and Infant Attachment: A Comparison Between Full-Term and Preterm Dyads. Child Psychiatry \& Human Development. 2015;46(2):320-331.

17. Faure N, Habersaat S, Harari MM, et al. Maternal Sensitivity: a Resilience Factor against Internalizing Symptoms in Early Adolescents Born Very Preterm? Journal of Abnormal Child Psychology. 2017;45(4):671-680.

18. Treherne SC, Feeley N, Charbonneau L, Axelin A. Parents' Perspectives of Closeness and Separation With Their Preterm Infants in the NICU. Journal of Obstetric, Gynecologic \& Neonatal Nursing. 2017;46(5):737-747.

19. Baum N, Weidberg Z, Osher Y, Kohelet D. No Longer Pregnant, Not Yet a Mother: Giving Birth Prematurely to a Very-Low-Birth-Weight Baby. Qualitative Health Research. 2012;22(5):595606.

20. Scime NV, Gavarkovs AG, Chaput KH. The effect of skin-to-skin care on postpartum depression among mothers of preterm or low birthweight infants: A systematic review and meta-analysis. Journal of Affective Disorders. 2019;253:376-384.

21. Edéll-Gustafsson U, Angelhoff C, Johnsson E, Karlsson J, Mörelius E. Hindering and buffering factors for parental sleep in neonatal care. Journal of Clinical Nursing. 2015;24(5/6):717-727.

22. Mörelius E, Anderson GC. Neonatal nurses' beliefs about almost continuous parent-infant skin-to-skin contact in neonatal intensive care. Journal of Clinical Nursing. 2015;24(17-

18):2620-2627. 
23. Athanasopoulou E, Fox JR. Effects of kangaroo mother care on maternal mood and interaction patterns between parents and their preterm, low birth weight infants: a systematic review. Infant Mental Health Journal. 2014;35(3):245-262.

24. Feldman R, Rosenthal, Z, Eidelman, A. Maternal-Preterm Skin-to-Skin Contact Enhances Child Physiologic Organization and Cognitive Control Across the First 10 Years of Life. Biological Psychiatry. 2014;75(1):56-64.

25. Neu M, Robinson J. Maternal Holding of Preterm Infants During the Early Weeks After Birth and Dyad Interaction at Six Months. Journal of Obstetric, Gynecologic, and Neonatal Nursing. 2010;39:401-414.

26. Chiu S-H, Anderson GC. Effect of early skin-to-skin contact on mother-preterm infant interaction through 18 months: Randomized controlled trial. International Journal of Nursing Studies. 2009;46(9):1168-1180.

27. Mörelius E, Örtenstrand A, Theodorsson E, Frostell A. A randomised trial of continuous skinto-skin contact after preterm birth and the effects on salivary cortisol, parental stress, depression, and breastfeeding. Early Human Development. 2015;91(1):63-70.

28. Mesman J, van ljzendoorn MH, Bakermans-Kranenburg MJ. The many faces of the Still-Face Paradigm: A review and meta-analysis. Developmental Review. 2009;29(2):120-162.

29. Tronick E, Als H, Adamson L, Wise S, Brazelton TB. The Infant's Response to Entrapment between Contradictory Messages in Face-to-Face Interaction. Journal of the American Academy of Child Psychiatry. 1978;17:1-13.

30. Ainsworth MD. Maternal Sensitivity Scales. The Baltimore Longitudinal Project. https://pdfs.semanticscholar.org/77ba/e53ad6d26d2fc13b02f144874cfa1ab28527.pdf. Published 1969. Accessed July 23, 2019.

31. Tryphonopoulos PD, Letourneau N, DiTommaso E. Caregiver-Infant Interaction Quality: A Review of Observational Assessment Tools. Comprehensive Child \& Adolescent Nursing. 2016;39(2):107-138.

32. Mesman J, Emmen R. Mary Ainsworth's legacy: a systematic review of observational instruments measuring parental sensitivity. Attachment \& Human Development. 2013;15(5/6):485-506.

33. National Institute for Health and Care Excellence. Children's Attachment: Attachment in Children and Young People Who Are Adopted from Care, in Care or at High Risk of Going into Care. NICE Guideline, No. 26. https://www.ncbi.nlm.nih.gov/books/NBK338143/. Published Nov 2015. Accessed August 28, 2019.

34. Cenciotti F, Tronick EZ, Reck C. Maternal Sensitivity and Responsivity Scales-R. Unpublished manuscript. Universitätsklinikum Heidelberg and Harvard Medical School, Boston. 2004.

35. Field A. Discovering statistics using IBM SPSS Statistics: and sex and drugs and rock ' $n$ ' roll. $4^{\text {th }}$ ed. United Kingdom, Europe: Sage; 2013.

36. Mörelius E, Theodorsson E, Nelson N. Salivary Cortisol and Mood and Pain Profiles During Skin-to-Skin Care for an Unselected Group of Mothers and Infants in Neonatal Intensive Care. Pediatrics. 2005;116(5):1105-1113.

37. Blomqvist YT, Rubertsson C, Nyqvist KH. Parent-infant skin-to-skin contact; How do parent records compare to nurse records? Acta Paediatrica. 2011;100(5):773-775.

38. Als H. Newborn Individualized Developmental Care and Assessment Program (NIDCAP): New frontier for neonatal and perinatal medicine. Journal of Neonatal-Perinatal Medicine. 2009;2(3):135-147.

39. Lehtonen L, Gimeno A, Parra-Llorca A, Vento M. Early neonatal death: A challenge worldwide. Seminars in Fetal and Neonatal Medicine. 2017;22(3):153-160.

40. Gathwala G, Singh B, Balhara B. KMC facilitates mother baby attachment in low birth weight infants. The Indian Journal Of Pediatrics. 2008;75(1):43-47.

41. Mörelius E, Angelhoff C, Eriksson J, Olhager E. Time of initiation of skin-to-skin contact in extremely preterm infants in Sweden. Acta Paediatrica. 2012;101(1):14-18. 
42. Bystrova K, Ivanova V, Edhborg M, et al. Early Contact versus Separation: Effects on MotherInfant Interaction One Year Later. Birth: Issues in Perinatal Care. 2009;36(2):97-109.

43. Mörelius E, Nelson N, Gustafsson PA. Salivary cortisol response in mother-infant dyads at high psychosocial risk. Child: Care, Health \& Development. 2007;33(2):128-136.

44. Meijssen D, Wolf M-J, Koldewijn K, et al. The effect of the Infant Behavioral Assessment and Intervention Program on mother-infant interaction after very preterm birth. Journal of Child Psychology \& Psychiatry. 2010;51(11):1287-1295.

45. Beebe $\mathrm{B}$, Myers MM, Lee $\mathrm{SH}$, et al. Family nurture intervention for preterm infants facilitates positive mother-infant face-to-face engagement at 4 months. Developmental Psychology. 2018;54(11):2016-2031.

46. Smith E, Bergelson I, Constantian S, Valsangkar B, Chan GJ. Barriers and enablers of health system adoption of kangaroo mother care: a systematic review of caregiver perspectives. BMC Pediatrics. 2017;17:1-16.

47. Evans T, Whittingham K, Sanders M, Colditz P, Boyd RN. Are parenting interventions effective in improving the relationship between mothers and their preterm infants? Infant Behavior and Development. 2014;37:131-154.

48. Bakermans-Kranenburg MJ, van ljzendoorn MH, Juffer F. Less is more: Meta-analyses of sensitivity and attachment interventions in early childhood. Psychological Bulletin. 2003;129(2):195-215.

49. Mountain G, Cahill J, Thorpe H. Sensitivity and attachment interventions in early childhood: A systematic review and meta-analysis. Infant Behavior and Development. 2017;46:14-32.

50. Shai D, Belsky J. When words just won't do: Introducing parental embodied mentalizing. Child Development Perspectives. 2011;5(3):173-180.

51. Kovan NM, Chung AL, Sroufe LA. The Intergenerational Continuity of Observed Early Parenting: A Prospective, Longitudinal Study. Developmental Psychology. 2009;45(5):12051213.

52. Blomqvist YT, Frölund L, Rubertsson C, Nyqvist KH. Provision of Kangaroo Mother Care: supportive factors and barriers perceived by parents. Scandinavian Journal of Caring Sciences. 2013;27(2):345-353.

53. Gulla K, Dahlø R, Eilertsen MEB. From the delivery room to the neonatal intensive care unitMothers' experiences with follow-up of skin-to-skin contact after premature birth. Journal of Neonatal Nursing. 2017;23(6):253-257.

54. Bakermans-Kranenburg MJ, Alink LRA, Biro S, Voorthuis A, van Ijzendoorn MH. The Leiden Infant Simulator Sensitivity Assessment (LISSA): Parenting an Infant Simulator as Your Own Baby. Infant and Child Development. 2015;24:220-227.

55. Kalinauskiene L, Cekuoliene D, van ljzendoorn MH, Bakermans-Kranenburg MJ, Juffer F, Kusakovskaja I. Supporting insensitive mothers: the Vilnius randomized control trial of videofeedback intervention to promote maternal sensitivity and infant attachment security. Child: Care, Health \& Development. 2009;35(5):613-623.

56. Koren-Karie N, Oppenheim D, Dolev S, Yirmiya N. Mothers of securely attached children with autism spectrum disorder are more sensitive than mothers of insecurely attached children. Journal of Child Psychology \& Psychiatry. 2009;50(5):643-650.

57. Fuertes $M$, Lopes-dos-Santos $P$, Beeghly $M$, Tronick E. Infant coping and maternal interactive behavior predict attachment in a Portuguese sample of healthy preterm infants. European Psychologist. 2009;14(4):320-331. 


\section{Figures and Tables}

Figure 1. Flow chart of study sample

Table 1: Demographic data of participating infants and mothers

Table 2: Skin-to-skin contact; hours/ day

Table 3: Ainsworth's Maternal Sensitivity Scale and MSRS-R, for continuous and

intermittent SSC respectively. Ainsworth's Maternal Sensitivity Scales ranging from 1.0-9.0.

MSRS-R ranging from 1.0-5.0. * The MSRS-R Withdrawal and Intrusivity scales are reversed.

Table 4: Correlation coefficients between mean time in SSC and interaction scales 
Figure. 1. Flow chart of study sample

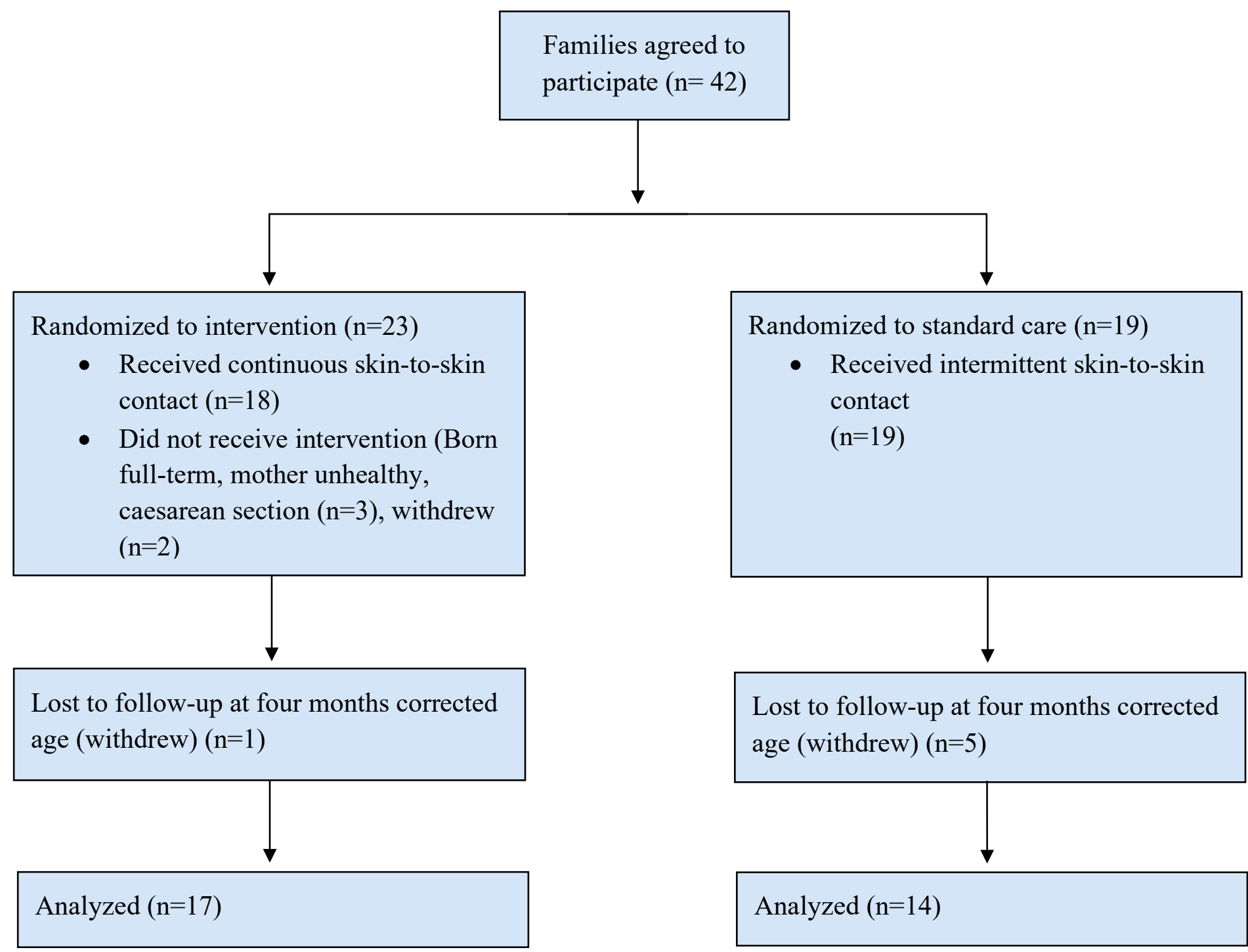


Table 1: Demographic data of participating infants and mothers

Table 1. Demographic data of participating infants and mothers

\begin{tabular}{|c|c|c|}
\hline & $\begin{array}{l}\text { Continuous SSC, } \\
n=17\end{array}$ & $\begin{array}{l}\text { Intermittent SSC, } \\
\mathrm{n}=14\end{array}$ \\
\hline Gender, boys/girls & $11 / 6$ & $6 / 8$ \\
\hline PMA at birth, mean (SD)/week & $243(5.8) / 34$ & $243(4.8) / 34$ \\
\hline PMA at discharge, mean (SD)/weeks & $263(7.6) / 37$ & $261(4.9) / 36$ \\
\hline Birth weight, g, mean (SD) & $2480(289)$ & $2519(246)$ \\
\hline Weight at discharge, g, mean (SD) & 2809 (345) & $2794(238)$ \\
\hline Weight four months, g, mean (SD) & $6930(654)$ & $6760(874)$ \\
\hline Siblings, yes/no/missing data & $4 / 12 / 1$ & $4 / 9 / 1$ \\
\hline Mother's age, years, mean (SD) & $31(3.4)$ & $32(5.8)$ \\
\hline Cohabitant/single/missing data & $17 / 0 / 0$ & $12 / 1 / 1$ \\
\hline $\begin{array}{l}\text { Mother's education, High } \\
\text { school/university/missing data }\end{array}$ & $2 / 15 / 0$ & $3 / 10 / 1$ \\
\hline Breastfeeding, yes/no/missing data & $13 / 4 / 0$ & $7 / 6 / 1$ \\
\hline $\begin{array}{l}\text { Edinburgh Postnatal Depression Scale, } \\
\text { mean (SD), missing data }\end{array}$ & $4.2(3.3) 1$ & $3.9(3.7) 0$ \\
\hline
\end{tabular}


Table 2. Skin-to-skin contact; hours/day

\begin{tabular}{|c|c|c|c|c|c|}
\hline & \multicolumn{2}{|c|}{ Continuous SSC } & \multicolumn{3}{|c|}{ Intermittent SSC } \\
\hline & $\mathrm{n}$ & Hours/day & $\mathrm{n}$ & Hours/day & $p$-value \\
\hline & & Mean (SD) & & Mean (SD) & \\
\hline Day 1 & 17 & $21.33(5.37)$ & 14 & $6.25(5.10)$ & $<0.001$ \\
\hline Day 2 & 17 & $21.46(5.37)$ & 14 & $6.96(5.66)$ & $<0.001$ \\
\hline Day 3 & 17 & $19.61(5.78)$ & 14 & $6.47(4.77)$ & $<0.001$ \\
\hline Day 4 & 16 & 19.45 (5.59) & 14 & $6.64(4.28)$ & $<0.001$ \\
\hline Day 5 & 16 & $20.32(6.00)$ & 13 & $6.09(3.89)$ & $<0.001$ \\
\hline Day 6 & 15 & $20.10(5.21)$ & 13 & $5.27(2.85)$ & $<0.001$ \\
\hline Day 7 & 14 & $16.22(8.03)$ & 12 & $6.52(2.88)$ & 0.001 \\
\hline
\end{tabular}


Table 3: Ainsworth's Maternal Sensitivity Scale and MSRS-R, for continuous and intermittent SSC respectively

\begin{tabular}{|llll|}
\hline $\begin{array}{l}\text { Table 3. Ainsworth's Maternal Sensitivity Scale and MSRS-R, for continuous and } \\
\text { intermittent SSC respectively }\end{array}$ & $\begin{array}{l}\text { Continuous SSC } \\
\mathrm{N}=17 \\
\text { Median (q1-q3) }\end{array}$ & $\begin{array}{l}\text { Intermittent SSC } \\
\mathrm{N}=14 \\
\text { Median (q1-q3) }\end{array}$ & p-value \\
\hline Ainsworth, Sensitivity & $5.0(3.0-8.0)$ & $5.5(3.0-7.0)$ & .98 \\
Ainsworth, Interference & $6.0(2.5-7.5)$ & $5.0(2.75-6.25)$ & .68 \\
Ainsworth, Availability & $6.0(3.0-8.5)$ & $6.0(3.0-9.0)$ & .83 \\
Ainsworth, Acceptance & $6.0(4.0-8.5)$ & $7.0(5.0-7.0)$ & .68 \\
MSRS-R, Sensitivity & $3.0(2.0-4.0)$ & $3.5(3.0-4.0)$ & .76 \\
MSRS-R, Withdrawal* & $1.0(1.0-2.0)$ & $1.5(1.0-2.0)$ & .42 \\
MSRS-R, Intrusivity* & $3.0(2.0-4.0)$ & $3.0(2.0-4.0)$ & $>.99$ \\
& & & \\
\hline
\end{tabular}

Ainsworth's Maternal Sensitivity Scale ranging from 1.0-9.0.

MSRS-R ranging from 1.0-5.0.

* The MSRS-R Withdrawal and Intrusivity scales are reversed. 
Table 4. Correlation coefficients between mean time in SSC and interaction scales

\begin{tabular}{lll}
\hline Interaction scales & Mean time SSC & Mean time SSC \\
& Day 1-3 & Day 1-7 \\
\hline Ainsworth, Sensitivity & -0.081 & -0.083 \\
Ainsworth, Interference & -0.024 & -0.147 \\
Ainsworth, Availability & -0.082 & -0.170 \\
Ainsworth, Acceptance & -0.128 & -0.187 \\
MSRS-R, Sensitivity & -0.07 & -0.144 \\
MSRS-R, Withdrawal & -0.095 & 0.096 \\
MSRS-R, Intrusivity & 0.121 & 0.162 \\
\hline
\end{tabular}

